COMMISSION No. 10

SOLAR ACTIVITY (ACTIVITE SOLAIRE)

COMMISSION No. 12

\title{
RADIATION AND STRUCTURE OF THE SOLAR ATMOSPHERE
}

\section{(RADIATION ET STRUCTURE DE L'ATMOSPHERE SOLAIRE)}

Report of Meetings on 3, 4, 5, 6 and 8 August 1988

PRESIDENT (10): M. Pick

SECRETARY (10): A. Benz

PRESIDENT (12): M. Kuperus

SECRETARY (12): J. Harvey

JOINT BUSINESS MEETING (5 August; 09:00-12:50, 17:40-18:05)

The President of Commission 12, M. Kuperus, opened the meeting by explaining that due to the close cooperation which exists between Commissions 10 and 12 and the strong overlap in membership, all activities of the two Commissions at the present General Assembly were organized jointly. He expressed his thanks to the Organizing Committee and vice president of Commission 12 for their aid in conducting the work of the Commission and to the President of Commisson 10, M. Pick, for her cooperation during the past three years. The following officers and organizing committees were elected for Commission 12: President: J.W. Harvey; Vice President: J.0. Stenflo; Organizing Committees: H. Ando, R. Falciani, Ai Guoxiang, E.A. Gurtovenko, M. Kuperus (past president), R. Muller, T. Roca Cortes, M. Schuessler, K.R. Sivaraman, N.O. Weiss. Applications for membership in Commission 12 by 31 individuals were accepted by acclamation. The Chairman of the Working Group on Eclipses presented the report found below.

The President of Commission 10, M. Pick, expressed her thanks to the Organizing Committee and vice president of Commission 10 and to M. Kuperus for their aid and cooperation. She reported that 72 applications for membership in Commission 10 were received of which 52 were from new IAU members. The following officers and organizing committee were elected for Commission 10: President: E.R. Priest; Vice President: V. Gaizauskas; Organizing Committee: E. Antonucci, A.0. Benz (secretary), S. Enome, 0. Engvold, Fang Chen, E.A. Gurtovenko, M. Machado, M. Pick (past president), E.A. TandbergHanssen.

M. Pick, IAU representative to COSPAR Subcommission E.2 reported on the recent COSPAR meeting and presented a list of symposia and workshops proposed for the COSPAR meeting in 1990. Some of these meetings have been proposed for IAU co-sponsorship. She also presented a list of proposed symposia and colloquia which have been recommended to the IAU Executive Committee for IAU sponsorship. M. Pick announced that nine future IAU colloquia and symposia have been approved by the executive committee on recommendation of Commissions 10 and 12 . 
The first volume of the continuation of the Greenwich Photoheliograph Results now produced by the Debrecen Observatory has appeared. L. Gesztelyi reported that serious budget cuts threaten this effort. Debrecen needs help from the IAU in obtaining film and a small computer. A resolution addressing this is sue was prepared (see below).

E. Hiei, the present editor of the Quarterly Bulletin on Solar Activity, reported on the history and current status of this IAUassisted publication: the Quarterly Bulletin on Solar Activity contains five parts: I Sunspots, II Synoptic Charts of Solar Magnetic Fields, III Eruptions Chromospheriques Brilliantes, IV Intensité de la Couronne Solaire, and V Solar Radio Emission.

Part $I$ is edited from the data of 74 observatories and institutes at the Sunspot Index Data Center, Bruxelles. Part II is reproduced from the daily solar magnetograms obtained at the Mount Wilson Observatory. H $\alpha$ flare data from 25 observatories are collected and compiled in Part III at the Meudon Observatory. Coronal intensities of 5303 line and 6374 line measured at 4 coronal observatories and the synoptic map of the coronal intensity are prepared in Part IV at the Kislovodsk Observatory. Part $V$ is compiled from the radio data of 39 observatories at the Research Institute of Atmospherics (Toyokawa).

Each part of QBSA is published when it is ready for printing. Part I, II, III, IV and $V$ are now published unt1l 1985, 1985, June 1982,1985 , and 1984 , respectively.

H. Coffey reported on IAU Commission 10 standing committees:

IUWDS Report

The IUWDS is a permanent service of URSI, IAU and IUGG which "aims to provide information rapidly to the world scientific community to assist in the planning, coordination, and conduct of scientific work in relevant disciplines". The current Chairman is Dr. Richard Thompson, IPS, Australia. Secretary is Gary Heckman, NOAA, ERL, Boulder. Secretary for World Days is Helen Coffey, NOAA, NESDIS, Boulder. The Steering Committee is made up of representatives from the worldwide network of Regional Warning Centers and Auxiliary Regional Warning Centers. Publications include the International Geophysical Calendar which recommends dates for solar and geophysical observations which cannot be carried out continuously. The Spacewarn Bulletin is issued montly by WDC-A for Rockets and Satellites in response to recommendations by COSPAR. Geoalerts and Ursigram messages are sent in real time by telex to Regional Warning Centers around the globe. This is the lifeblood of the IUWDS network. Expenses are borne by the host institutions. In addition, IUWDS holds workshops on solar terrestrial predictions. The 1984 Workshop in Meudon resulted in a 636 page Proceedings and a special edition of Artificial Satellites in 1987 by the Polish Academy of Sciences Space Research Centre. The next Workshop is planned for October 1989 in Leura, Australia (near Sydney). IUWDS provides a number of very useful services to the solar community, and is always open to suggestions on how to better fit the needs of the scientific community.

Solar Interplanetary Variability (SIV)

The SIV program, 1988-1990, sponsored by SCOSTEP, is international, interdisciplinary and includes spacecraft and ground-based 
observations. It is an effort to look at the transition between solar minimum and solar maximum. At minimum, the large scale solar wind structure consists principally of a few recurrent streams which corotate with the Sun. At maximum, changes in the solar wind are dominated by transient events that occur in intervals much less than one solar rotation. SIV looks at how it evolves from one to the other. More computer networking is encouraged to exchange and analyze scientific data. Workshops will be held to study specific events and/or the evolution of solar-interplanetary structures. Sunspot Index Data Center (SIDC), Belgium

The SIDC produces the dafly International Sunspot Number Ri. It broadcasts a monthly provisional number within 24 hours following the end of each month. It also forecasts $R i \quad 6,9$ and 12 months ahead as requested by CCIR. Quarterly, it issues the final International Sunspot Number Ri. For the IAU QBSA it provides Ri, Rc (an index for the central zone of the disk), and also an estimate of the daily sunspot area. 90 stations currently submit data for the Ri. The SIDC monthly "Sunspot Bulletin" is mailed to 350 addresses before the sixth of the month. The latest forecast of sunspot maximum is $170 \pm 25$ in September 1989. The work of the engaged data collectors and their great service for the community is acknowledged by the President.

S.T. Wu reported on planned SCOSTEP activities, including STEP (Solar-Terrestrial Energy Program) planned for 1990-5, and the next Solar Terrestrial Physics Symposium to be held in 1990 at the next COSPAR meeting. He also described organizational changes of SCOSTEP including a change of its constitution, the proposed organization of STEP and the relation of SCOSTEP to the International Geosphere Biosphere Program. Wu is reelected to represent the IAU in SCOSTEP.

The activity and budget of FAGS (Federation of Astronomical and Geophysical Data Services) are highlighted by E.A. Tandberg-Hanssen. Report from FAGS

The Federation of Astronomical and Geophysical Data Analysis Services (FAGS) was established by ICSU to oversee the activities of the following services.

International Earth Rotation Service, IERS

Quarterly Bulletin of Solar Activity, QBSA

Int1. Service for Geomagn. Indices, ISGI

Permanent Service for mean sea level, PSMSL

Bureau Gravimétrique international, BGI

Intl. Centre for Earth Tides, ICET

Int1. Ursigram and World Days Service, IUWDS

World Glacier Monitoring Service, WGMS

Sunspot Index Data Centre, SIDC

Centre de Données Stellaires, CDS

of these series, the QBSI, IUWDS and SIDC are of direct interest to Commission 10, and they receive a modest financial support from FAGS.

The IAU is represented on the FAGS council by Drs. Kovalevsky and Tandberg-Hanssen. At the Commission 10 and 12 joint business meeting on 5/8/88, Tandberg-Hanssen gave a report on the activities of FAGS 
since the 19th General Assembly. After the nomination by the President of commission 10 for Tandberg-Hanssen to continue to represent IAU on the FAGS council for the following 3 years, Tandberg-Hanssen was so elected.

J.C. Pecker presented two resolutions for consideration by Commissions 10 and 12 . The first resolution was accepted:

Resolution of Commissions 10 and 12

Considering

the scientific importance of insuring a continuous survey, over a long period of time, of solar phenomena as observed in photospheric, chromospheric and coronal layers, in the solar wind and in solarterrestrial relations;

recommends

a) the pursuit of these types of continuous observations wherever they are already conducted,

b) their undertaking in other observatories especially in consideration of broad longitude coverage to insure continuity,

c) financial assistance by the IAU for the particular programs which have previously been recommended by Commissions 10 and 12 , and in particular the essential Debrecen photoheliograph surveys which face a difficult financial situation.

The second resolution concerning long term astrometric measurement of the solar diameter did not receive enough support for passage.

B. Dennis reported on the Flares 22 program sponsored by SCOSTEP under the umbrella of STEP. The Chairman is M. Machado and a steering committee will be determined. A resolution to have this program recognized by the IAU is unanimously accepted:

Resolution of Commission 10

Recognizing

the value of a coordinated scientific programme for the study of physical processes and mechanisms heading to solar active phenomena and flares, and recognizing further that most of these processes and mechanisms are common to a large variety of astrophysical objects and are responsible for interplanetary phenomena which affect the terrestrial environment.

Noting:

that a comprehensive study of all these components of solar activity exceeds the capabilities of any single country.

Further noting that several countries - the USA, USSR' and People's Republic of China - already have written plans for coordinated studies during the next solar maximum, and that they have expressed their willingness to participate in a coordinated international campaign.

Commission 10

proposes that the IAU cosponsors the Flare 22 programme, to be in effect during the maximum of solar cycle 22 under the umbrella of SCOSTEP's Solar Terrestrial Energy Programme (STEP) 
also recommends that a member of Commission 10 be appointed to the Flare 22 steering committee.

The Presidents of Commissions 10 and 12 then described concerns voiced at the IAU Commission President's meeting. A declining attendance and interest in the general assembly, particulary among young astronomers, were of particular concern. A lively discussion followed with several proposals offered from the floor. Among these were suggestions to have more one day meetings, allow contributed papers to be presented, publish papers from the meetings in the manner of COSPAR, reduce meeting competition with COSPAR, and improve information about the content of meetings prior to the meeting.

A discussion of a merger of Commissions 10 and 12 into a single commission on the Sun occupied the remainder of the business meeting. The Presidents of Commissions 10 and 12 stated that the division of solar research into different domains is not justifiable on scientific grounds. The activity of the solar commissions could be improved if forces were joined. Thus, they propose a merger. A vigorous discussion followed with both supporting and dissenting views expressed. The prevailing view was support for the merger on scientific grounds but concern about weakening the political role of solar research in respect to other astronomical research presented by IAU commissions. A straw vote favoured merger by a ratio of more than two to one, however since less than $5 \%$ of the membership of the Commissions was present, the following resolution was adopted:

The joint meeting of Commissions 10 and 12 supports in principle the merger of the two Commissions. The meeting further requests the organizing committees of the two Commissions to produce within the next twelve months a specific proposal for such a merger, that this proposal be put to a postal ballot of the members of the two commissions and if supported by a majority of those voting in each commission then the proposal be forwarded to the IAU Executive Committee as a formal proposal for the merger of Commissions 10 and 12.

\section{SCIENTIFIC MEETINGS}

1. Solar and Stellar Coronae (4 August; 09:00-12:30, 14:00-17:30)

This Joint Commission Meeting (Commissions 10, 12, 29, 35, 36, 44) was organized by R. Falciani and E. Priest. The meeting was dedicated to the memory of the late Gordon Newkirk, Jr. and consisted of invited papers and contributed posters. Publication will be in the Transactions of the IAU.

2. Large-Scale Computer Simulation of Solar Active Phenomena (5 August; $14: 00-17: 30$ )

This joint meeting sponsored by Commissions 10 and 12 was organized by G. van Hoven and S.T. Wu. A summary will be given in the transactions of the IAU.

3. Results of Systematic Observations of the Sun (8 August; 09:00$12: 30,14: 00-17: 30$. 
This joint meeting sponsored by Commissions 10 and 12 was organized by J.C. Pecker and P. Wilson. The meeting was dedicated to Prof. Helen Dodson Prince who was unfortunately unable to attend. Both invited papers and contributed posters were presented. A summary will be given in the transactions of the IAU.

WORKING GROUP ON ECLIPSES (1985-1988)

Chairman: E. Hiei

Several eclipses occurred during 1985-88, but the total eclipse of 13 March 1988 in Indonesia, the Philippines, and the north-west Pacific, was scientifically attractive. There was a Philippine National Committee for the eclipse.

Before the next General Assembly in 1991, two total eclipses will occur: one on 22 July 1990 in Finland and U.S.S.R., the other on 11 July 1991 in Hawaii, Mexico, Central America, Colombia, and Brazil.

The Working Group held meetings on 3 and 6 August to discuss the astronomical information concerning the eclipses, scientific objectives, and a Coordinator who may assist members in obtaining nonastronomical information as well as logistic assistance, and to exchange information on the possible observing sites. 